\title{
PowerEnergy2018-7112
}

\section{THE IMPACT OF LACK OF CLEAN COOKING FUELS ON SUSTAINABLE DEVELOPMENT IN DEVELOPING COUNTRIES}

\author{
Ifeoluwa Garba* \\ Centre for Doctoral Training Wind \& Marine Energy Systems \\ Department of Electrical and Electronic Engineering \\ University of Strathclyde \\ Glasgow, United Kingdom \\ Email: ife.garba@strath.ac.uk
}

\author{
Richard Bellingham \\ Institute of Future Cities \\ University of Strathclyde \\ Glasgow, United Kingdom \\ Email: richard.bellingham@strath.ac.uk
}

\begin{abstract}
Access to energy is crucial in tackling many of the current global development challenges that impact on people's economic, health and social well-being as well as the ability to meet the commitments of reducing carbon emissions through clean energy use. Despite increased attention from multiple governments and agencies, energy poverty remains a serious sustainable development issue in many developing countries. To date, most research have focused on general access to electricity and the generation of clean energy to replace fossil fuels, failing to address the lack of basic access to clean energy for cooking and heating. More people in the world lack access to clean cooking fuels than to electricity. This issue is one aspect of a broader research which investigates the impacts of optimized energy policy and energy business models on sustainable development in developing countries.
\end{abstract}

\section{INTRODUCTION}

Access to modern forms of energy is essential for sustainable social development and is instrumental in urbanization and industrialization: vital factors for economic development [1-3]. In addition, it plays a vital role in enabling a sustainable environment. Yet, billions of people across the globe currently lack access to modern forms of energy for basic day-to-day activities such as lighting and cooking [4]. As such, there has been

\footnotetext{
*Address all correspondence to this author.
}

increased focus on attaining universal access to modern energy services [5]. However, most of these efforts have been narrow. Up to date, more emphasis have been placed on access to electricity for lighting, neglecting access to clean fuels for cooking and heating; a cause and effect of more people lacking access to clean cooking fuels than electricity, across the world [6]. This disregard of the phenomenon can be exemplified by governmental goals, targets and documents which tend to include the enabling of access to electricity but omit access to clean cooking fuels [7].

Further effects include the significant gap in the analysis of the impacts of lack of clean cooking fuel on social and economic development; especially in developing countries where such developments are much needed. Of the few, existing literature which have examined the impacts of the lack of access to clean fuels for cooking and/or heating, most have placed emphasis on the environmental impacts such as global and/or local pollution, whilst placing less focus on the socio-economic effects of the situation on people's lives. At most, studies have mentioned the health impacts of heavy reliance on solid fuels for cooking, providing little to no analysis of other social and economic impacts such as education and employment.

Consequently, this paper tries to address some of these gaps and thus contribute to literature, through reviewing the limited, existing literature on socio-economic impacts of lack of clean fuels for cooking and/or heating. In addition, we quantitatively evaluate impacts of the use of solid fuels for cooking and heating, on some indicators which have been reported to impact eco- 
nomic development. We analyse the correlation between the use of solid fuels and primary education enrolment, secondary education enrolment, employment as well as life expectancy.

\section{WIDER VIEW OF ENERGY ISSUES}

It is a shocking reality that billions of people lack access to basic energy services such as lighting, clean cooking and heating provisions. Currently, globally, approximately 1.2 billion people lack access to electricity, while about 2.8 billion people rely on the traditional use of biomass for cooking and/or heating (Tab 1). More people across the world lack access to clean cooking fuels than to electricity. The distribution of population affected by this issue is uneven, with the majority of the population residing in developing regions. Although the biggest component of the phenomenon is found in these regions; particularly in developing asia, where over 1.8 billion people lack access to clean cooking fuels and Sub-Sahara Africa, where almost 800 million people lack access [4]; this phenomenon is not exclusive to developing regions only. Some developed or transitioning countries, notably China, with low rates of lack of access to electricity, still have large proportions of the population relying on the traditional use of solid fuels for cooking.

The total energy consumption across the world in 2016 is evaluated and presented in Fig 1.

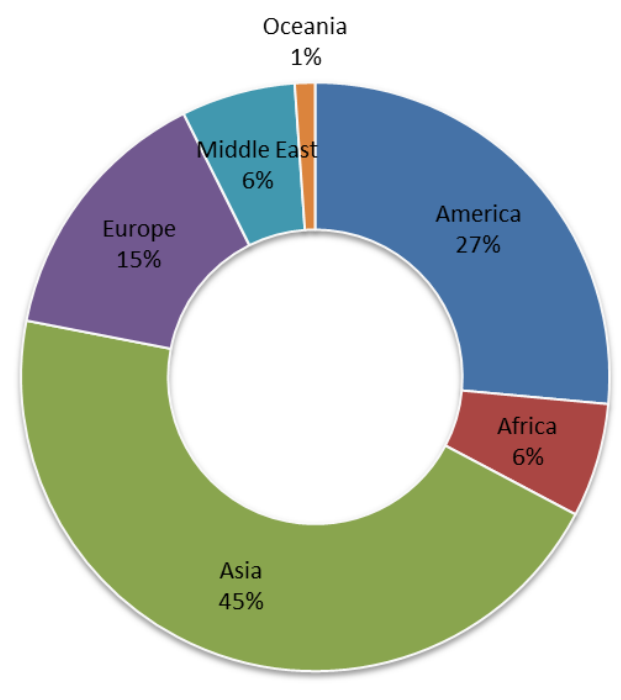

FIGURE 1. TOTAL ENERGY CONSUMPTION, 2016

The observed consumptions in Asia and America are in line with expectations. Considering that energy consumption tends to be driven by the population and economic activities within a region $[8,9]$, high levels of energy consumption within these regions can be expected. With regards to the regions with low consumption; the Oceania region which accounts for $0.54 \%$ [10] of the global population accounted for about $1 \%$ of the global energy consumption. However, striking is the consumption in Africa, where approximately $17 \%$ of the global population [10] account for only $6 \%$ of the global energy consumption. In other words, the approximately 1.2 billion people [10] within the region, consume less than half of the energy consumed by approximately 738 million [10] people in Europe. Considering that energy is instrumental for economic and social development and stability, if the economic potential within the region is to be realised, energy consumption will need to increase.

In terms of the composition of the fuel sources utilised in energy production and consumption, fossil fuels remain the largest energy source in the world, accounting for approximately $80 \%$ of the global energy consumption in 2016 (Fig 2). Yet, although focus is being placed on increasing the share of renewable energy in the global energy mix and thus shifting towards cleaner energy sources [7], with the exception of Africa, the energy mix across the regions remains dominated by coal, crude and natural gas.

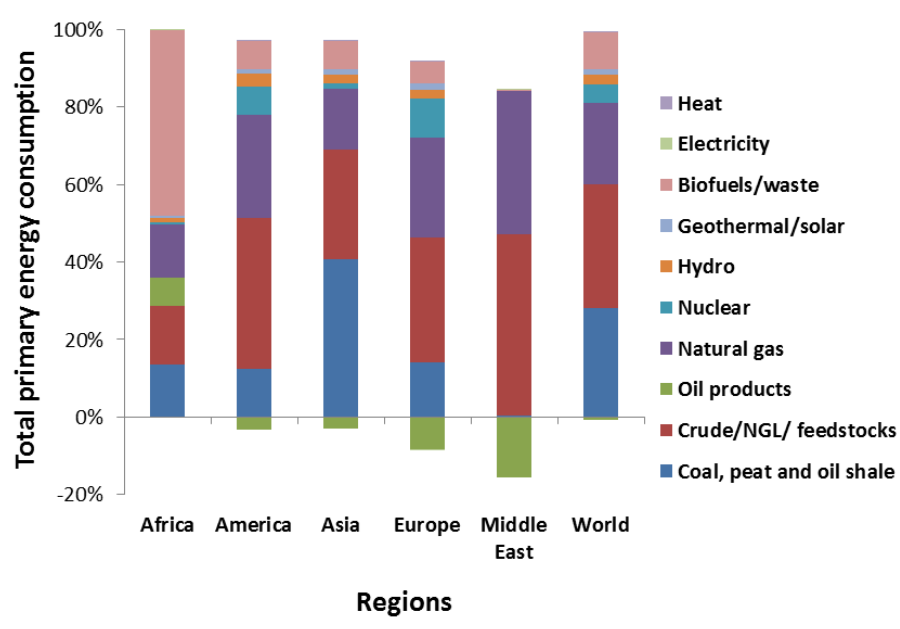

FIGURE 2. TOTAL PRIMARY ENERGY CONSUMPTION BY FUELS, 2016

Nonetheless, in their energy mix, Africa and the Middle East are heavily undiversified. In Africa, biofuels and wastes accounted for over $50 \%$ of total energy consumed within the region in 2016 (Fig 2). When only the Sub-Saharan region is considered, the share increases to approximately $70 \%$ and increases further to approximately $80 \%$ if South Africa is excluded. Considering the distribution of energy consumption based on only biofuels (Fig 3), the implication of this lack of diversification in fuel sources is illustrated. Taken together, for a region which 
contributes to only $4 \%$ of the total global energy consumption, contributing over 20 percent of the overall biofuels used in the world is very significant and illustrates a substantial imbalance in energy mix within the region. This serious imbalance in energy mix translates to the heavy reliance on solid fuels within households.

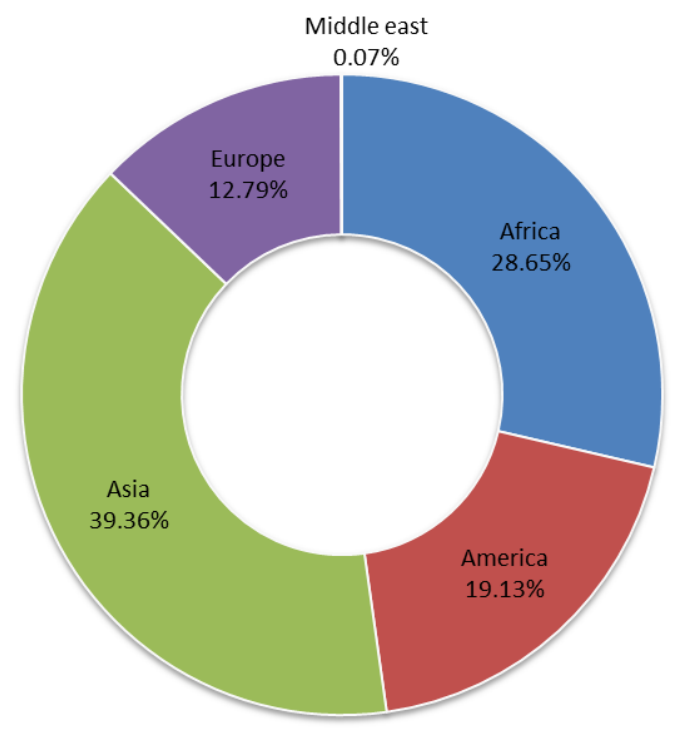

FIGURE 3. BIOFUELS CONSUMPTION ACROSS THE WORLD, 2016

The implication of this issue is further amplified by the fact that of the estimated 377 million tonnes of oil equivalent (Mtoe) of solid biomass used in Africa ${ }^{1}$; 280 Mtoe in Sub-Sahara, approximately $90 \%$ is consumed by households. What's more, cooking accounts for over $80 \%$ of the overall energy consumed within households [11]. Solid fuels such as firewood, straw, dried animal and human wastes tend to be the common fuels used within the region. Yet, the majority of these tend to be unprocessed and in most cases, are used in conjunction with inefficient, traditional cook-stoves thus, resulting in significant economic, social and health consequences.

The reasons for the heavy reliance on solid fuels for cooking are multifaceted and vary across regions. Nonetheless, it is anticipated that over the next two decades, with current policies, there will be little-to-no progress in this regard [12]. Hence, it is anticipated that by 2030, there could be an increase in the amount of people across the world, relying on solid fuels for cooking.

\footnotetext{
${ }^{1}$ Source: IEA database
}

TABLE 1. POPULATION WITHOUT ELECTRICITY AND RELYING ON TRADITIONAL USE OF SOLID FUEL, 2014 (MILLIONS).

\begin{tabular}{lcc}
\hline \hline Region & $\begin{array}{c}\text { Population } \\
\text { without } \\
\text { electricity }\end{array}$ & $\begin{array}{c}\text { Population relying on } \\
\text { traditional use of biomass } \\
\text { for cooking }\end{array}$ \\
\hline Africa & 634 & 793 \\
Sub-Saharan & 632 & 792 \\
Other & 1 & 1 \\
Developing Asia & 512 & 1,875 \\
India & 244 & 453 \\
Europe & 0 & 819 \\
Latin America & 22 & 0 \\
Middle East & 18 & 65 \\
\hline World & 1,186 & 2,742 \\
\hline \hline
\end{tabular}

\section{BARRIERS}

Demand for energy is exponentially increasing in developing countries, due to fast economic expansions (particularly in India and China) and population growth [13]. However, these increasing demands are left unmet due to various factors, which vary temporally, spatially and culturally. Notwithstanding, findings suggest that the predominant contributing factors common across all regions tend to be the lack of infrastructure; lack of government policies; financal limitations (at national and households levels) and a general lack of attention at household, national and international levels $[6,12]$. Yet, whilst there are other factors such as behavioural, cultural as well as socio-economic factors, here, we focus on external factors that are beyond the control of households. In addition, albeit these factors are separately presented, they are indeed closely interrelated.

\section{Infrastructure}

The under-developed nature or complete lack of infrastructures in developing regions can be termed a dominant impediment to the distribution of clean fuels for cooking and/or heating [14]. The effect of inadequate energy infrastructure is particularly pronounced in rural areas, where there is an extensive lack of distribution network, resulting in a higher rate of inaccessibility to modern fuel alternatives [13]. The influence of energy distribution infrastructures is further demonstrated in findings which have associated the higher use of commercial fuels such as LPG, in urban areas, to presence of adequate infrastructure $[14,15]$. 
In addition to the poor or lacking energy infrastructures, inadequate transportation infrastructures; particularly roads, are reported to be a major contributing factor to the lack of modern fuel alternatives [16]. For instance, in Sub-Sahara Africa where just over $10 \%$ of rural roads are paved [17], even if modern fuels were supplied, high transportation costs would be inevitable [18]. These are costs which are passed on to consumers.

Besides the inaccessibility and non-affordability effects, inadequate transportation infrastructures can also be associated to the unreliability element of the problem. This is particularly true in parts of rural Asia and Africa, where during particular seasons, such as the rainy season, poor roads make the areas inaccessible [19]. The implication of the lack of transport infrastructure can be viewed as two-fold. From a cost point of view, the scarcity caused by such disruption in supply, could result in increased demand and reduced supply. Thus, resulting in a shift to the equilibruim price of the fuels [20] which translates to higher purchase costs for consumers. Furthermore, the importance of ease of access and reliability of fuel sources for households has been studied and analysed by several studies [21,22] and findings suggest that the reliability of supply plays a role in the decision of households when considering fuel sources [23, 24]. Consequently, from a demand perspective, the lack of reliability and security of supply could defer households from switching to modern cooking fuel alternatives.

\section{Finance}

The implications of financial limitations can be viewed from both the supply and demand perspectives of clean cooking fuels. In terms of supply, limitations in funding affects the potentialities of developing the infrastructures needed for the adequate supply of modern fuels.

From the perspective of consumers, due to high costs, the switch to modern forms of cooking options becomes impeded for many households. Table 2 shows some associated costs for various cooking options, as per the study by Jeuland et.al [25]. For 'investment costs', we use the calculated mid values while for 'fuel costs' and 'consumption per household', the ranges of values are used for the different cooking options. It is not surprising that the lowest investment cost is associated with the traditional use of fuelwood since it can be assumed that households can either collect such fuel from nearby lands [26] or pay a low purchasing price. Nonetheless, although long term, this option requires the highest consumption of fuel; from an immediate cost perspective, low fuel costs combined with low investment costs make fuelwood an attractive energy source for most households in developing countries [26]. With the exception of perhaps the LPG and Kerosene options, the lofty investment costs associated with alternative cookstoves such as electrical stoves can be inferred to seriously impede the possibility of households to switch to such alternatives.
The significance of costs is intensified by the fact that the majority of people lacking access live in the poorest regions of the world [4]. The implication of this is further evidenced in the findings from the household survey carried out by Energy Sector Management Assistance Program (ESMAP) which supports that more than $70-80 \%$ of households in affected regions are unable to afford the switch from traditional fuels to cleaner cooking options due to the high initial costs [26]. In addition to steep investment costs, high fuel costs for cooking options such as kerosene and LPG, could further dissuade households from switching to such alternatives.

TABLE 2. COSTS ASSOCIATED TO VARIOUS COOKING OPTIONS [25]

\begin{tabular}{|c|c|c|c|}
\hline & $\begin{array}{l}\text { Invest- } \\
\text { ment } \\
\text { cost }(\$)\end{array}$ & $\begin{array}{l}\text { Fuel } \\
\text { cost } \\
(\$ / \mathrm{kg})\end{array}$ & $\begin{array}{c}\text { Consumption } \\
\text { per household } \\
\text { (toe/year) }\end{array}$ \\
\hline \multicolumn{4}{|c|}{ Traditional cookstoves } \\
\hline Charcoal & $3-6$ & $\begin{array}{l}0.1- \\
0.8\end{array}$ & $0.5-1.9$ \\
\hline Fuelwood, straw & $0-2$ & $\begin{array}{l}0.03- \\
0.2\end{array}$ & $1.0-3.7$ \\
\hline \multicolumn{4}{|c|}{ Improved cookstoves } \\
\hline Charcoal & 14 & $\begin{array}{l}0.1- \\
0.8\end{array}$ & $0.4-1.5$ \\
\hline Fuelwood & 15 & $\begin{array}{l}0.03- \\
0.2\end{array}$ & $0.5-1.6$ \\
\hline \multicolumn{4}{|c|}{ Alternative cookstoves } \\
\hline Kerosene & 30 & $\begin{array}{l}0.3- \\
0.7\end{array}$ & $0.1-0.2$ \\
\hline LPG & 60 & $\begin{array}{l}0.4- \\
1.0\end{array}$ & $0.08-0.15$ \\
\hline Electricity & 300 & $\begin{array}{l}0.03- \\
0.10\end{array}$ & $0.07-0.13$ \\
\hline Biogas digester & $\begin{array}{l}600- \\
1,500\end{array}$ & & $0.07-0.14$ \\
\hline
\end{tabular}

\section{EFFECTS AND IMPACTS}

To investigate the effects of the use of solid fuels on socioeconomic development, we provide an econometric panel model using the aggregate data from the regions of the world; over a period between 2000 and 2015. In terms of the aspects of socioeconomic development investigated, we analyse impacts on ed- 
ucation, employment and life expectancy. These elements of socio-economic development to be analysed, have been selected based on the focus areas of the United Nation's (UN) sustainable development goals [7].

The impacts of education and employment on economic development is a well researched topic, with evidences that conclude that the cognitive skills of the population within a country are strongly related to individual earnings, income distribution and thus, economic growth [27-29]. As a result, we investigate the impacts of the traditional use of solid fuels on education and employment: to understand how the use of solid fuel impacts economic development as well as its impact on life expectancy. Existing studies have investigated only the impacts of solid fuel on indoor pollution and thus, mortality rates. As such, existing literature on the subject matter is exiguous.

To address this gap, the aforementioned indicators are used as explanatory variables in our model. Their descriptive summary is presented in Tab 3.

For the 'solid fuel' variable, the variance of 'access to clean cooking fuels and technology' data was used as a proxy. However, it is worth noting that even with access to clean cooking fuel, some households might still rely on solid fuels for cooking (see 'Barriers' section). As such, there exists a possibility of negligible imperfection in the variable.

TABLE 3. Descriptive summary of variables

\begin{tabular}{lccccl}
\hline \hline Variables & $\mathrm{N}$ & $\mathrm{Min}$ & $\mathrm{Max}$ & Mean & Std. dev \\
\hline $\begin{array}{l}\text { Solid fuels } \\
\begin{array}{l}\text { Primary } \\
\text { education }\end{array}\end{array}$ & 105 & 0.00 & 88.79 & 33.82 & 33.30 \\
$\begin{array}{l}\text { Secondary } \\
\text { education }\end{array}$ & 105 & 60.23 & 97.97 & 90.93 & 9.04 \\
$\begin{array}{l}\text { Employment } \\
\text { Life expectancy }\end{array}$ & 105 & 40.87 & 70.48 & 57.47 & 7.80 \\
\hline \hline
\end{tabular}

For these analyses, we designed three (3) one-variable estimator models: the least squares, fixed effect and random effect models, to test the effects on each indicator. The least square model demonstrates the effects of the use of solid fuels on all the regions taken together; the fixed effect model demonstrates the effect within the regions while the random effects model demonstrates the effect within and across the regions, across the time period.

The results obtained from all models are presented in Tab 4, 5, 6,7 . However, although the estimates of the coefficients across all models are statistically significant; using the Lagrange multi-
TABLE 4. Effects of solid fuel use on primary education.

Primary Education enrolment (PENR)

\begin{tabular}{|c|c|c|c|}
\hline \multicolumn{4}{|c|}{ Models } \\
\hline $\begin{array}{l}\text { Effect } \\
\text { Specification }\end{array}$ & Pooling & $\begin{array}{l}\text { Fixed Effect } \\
\text { (FE) }\end{array}$ & $\begin{array}{l}\text { Random } \\
\text { Effect (RE) }\end{array}$ \\
\hline Coefficient & -0.20000 & -0.53977 & -0.28766 \\
\hline Std. Error & 0.018 & 0.11895 & 0.062499 \\
\hline t-Statistic & -11.017 & -4.538 & -4.6026 \\
\hline f-Statistic & 121.376 & 20.5935 & 21.1841 \\
\hline p-value & $<2.22 \mathrm{e}-16$ & $1.63 e-15$ & $1.19 \mathrm{e}-05$ \\
\hline R-squared & 0.54095 & 0.17512 & 0.17059 \\
\hline $\begin{array}{l}\text { Adjusted } \\
\text { R-squared }\end{array}$ & 0.53649 & 0.1156 & 0.16253 \\
\hline
\end{tabular}

TABLE 5. Effects of solid fuel use on secondary education.

Secondary Education Net enrolment (sec)

\begin{tabular}{llll}
\multicolumn{4}{c}{ Models } \\
$\begin{array}{l}\text { Effect } \\
\text { Specification }\end{array}$ & Pooling & $\begin{array}{l}\text { Fixed Effect } \\
(\text { FE) }\end{array}$ & $\begin{array}{l}\text { Random Effect } \\
(\mathrm{RE})\end{array}$ \\
\hline Coefficient & -0.54799 & -1.16936 & -0.93355 \\
Std. Error & 0.0266 & 0.089707 & 0.07651 \\
t-Statistic & -20.602 & -13.035 & -12.202 \\
f-Statistic & 424.425 & 169.919 & 148.881 \\
p-value & $<2.2 \mathrm{e}-16$ & $<2.2 \mathrm{e}-16$ & $<2.2 \mathrm{e}-16$ \\
R-squared & 0.8047 & 0.63659 & 0.59108 \\
$\begin{array}{l}\text { Adjusted } \\
\text { R-squared }\end{array}$ & 0.8028 & 0.61037 & 0.58711 \\
\hline \hline
\end{tabular}

plier and Hausman tests, the most efficient model was obtained to be the fixed effect model.

To demonstrate the impacts of the solid fuel on the variables (indicators), the parameters of interest are: coefficient, $R$-squared and most importantly, the $p$-values. The coefficient parameter indicates the marginal change expected in the dependent variable (e.g. primary education) as a result of a unit change in the independent variable (solid fuels). R-squared demonstrates how much of this observed variation is explained by the estimator and 
TABLE 6. Effects of solid fuel use on employment.

\begin{tabular}{llll}
\hline \hline \multicolumn{4}{c}{ Employment of population (emp) } \\
& \multicolumn{2}{c}{ Models } \\
\hline $\begin{array}{l}\text { Effect } \\
\text { Specification }\end{array}$ & Pooling & $\begin{array}{l}\text { Fixed Effect } \\
\text { (FE) }\end{array}$ & $\begin{array}{l}\text { Random Effect } \\
\text { (RE) }\end{array}$ \\
\hline Coefficient & 0.10700 & 0.09754 & 0.09977 \\
Std. Error & 0.021 & 0.05109 & 0.04443 \\
t-Statistic & 5.2074 & 1.9094 & 2.2455 \\
f-Statistic & 27.1169 & 3.6456 & 5.04246 \\
p-value & $9.85 \mathrm{e}-07$ & 0.05917 & 0.02687 \\
R-squared & 0.2084 & 0.0362 & 0.04667 \\
Adjusted & 0.2007 & -0.0333 & 0.03741 \\
R-squared & & & \\
\hline \hline
\end{tabular}

TABLE 7. Test results of the effects of solid fuel use on life expectancy.

\begin{tabular}{llll}
\hline \hline \multicolumn{4}{c}{ Life expectancy (life) } \\
\multicolumn{4}{c}{ Models } \\
\hline $\begin{array}{l}\text { Effect } \\
\text { Specification }\end{array}$ & Pooling & $\begin{array}{l}\text { Fixed Effect } \\
\text { (FE) }\end{array}$ & $\begin{array}{l}\text { Random } \\
\text { Effect (RE) }\end{array}$ \\
\hline Coefficient & -0.19267 & -0.4087 & -0.30325 \\
Std. Error & 0.01132 & 0.04704 & 0.03525 \\
t-Statistic & -17.016 & -8.6876 & -8.6027 \\
f-Statistic & 289.559 & 75.4746 & 74.0056 \\
p-value & $<2.22 \mathrm{e}-16$ & $9.09 \mathrm{e}-14$ & $9.29 \mathrm{e}-14$ \\
R-squared & 0.7376 & 0.4376 & 0.4181 \\
Adjusted & 0.7351 & 0.3970 & 0.41245 \\
R-squared & & & \\
\hline \hline
\end{tabular}

$p$-value tests the hypothesis that each coefficient is different from zero (0). Hence, to reject the null hypothesis that there is no link between the dependent and independent variables and thus confirm that the coefficients are not equal to zero (0), the $p$-value must be less than 0.05 .

Table 4 shows the effect of the use of solid fuels on primary education enrolment and it can be observed that across all models, there is a significant effect on primary education. How- ever, focusing on the fixed effect model, the results suggest that an increase in the use of solid fuel, would result in a decrease in primary school enrolment by a significant amount. Considering reports suggest children and women could spend up to 7 hours daily collecting fuels [12], this result would indicate that the use of solid fuel negatively impacts the possibility of children obtaining primary education. However, the impact of solid fuel on education is observed to be more acute when considering secondary education. Across all models in Tab 5, a more than doubling effect is observed in the coefficient parameters. Furthermore, lower $p$-values are obtained, implying that the models strongly reject the null hypothesis and the higher values of $R$-squared indicate the variations are strongly related to the estimators.

The results obtained for the effects on employment were interesting but inconclusive. Across all models, some positive effects on employment were observed. However, since the $p$-value for the fixed model was close to 0.05 , we can not conclude that the effects on employment are significant enough. As such, further modelling and tests would be advantageous to explore the effect of solid fuels on employment.

Finally, in terms of life expectancy, a significant negative effect is observed across all models, with the most significant effect found in the fixed effect model. Thus suggesting that the most effect is observed within the estimators. The results obtained from this analysis thus supports previous studies which report a high correlation and causal effect between indoor pollution caused by solid fuel use and respiratory diseases, lungs cancer as well as child mortality rates.

\section{DISCUSSION AND CONCLUSION}

In this paper, we have investigated the effects of the use of solid fuels on education, employment and life expectancy. Although the magnitude of the effects vary across the various indicators of interest, the obtained results show that the use of solid fuel has a significant impact on all examined indicators. With the exception of the employment indicator, which shows a positive effect, the use of solid fuel has been observed to produce negative effects on all examined indicators.

In terms of the implications of these results, the results obtained for the employment variable are particularly interesting. Due to the $p$-value of this result, the impact if termed weakly significant. Yet, regardless of the magnitude of the obtained coefficient, the fact that the results insinuate that a unit change in the use of solid fuel would increase employment, instigates further questions. Although one could speculate that an increase in the demand of solid fuels such as wood, could lead to an increase in labour demand, there is no conclusive evidence to support this would be the case. As such, further qualitative and quantitative analysis investigating the topic might be beneficial.

Across other variables, the most significant impacts have been observed in primary and secondary education enrolment rates. 
From our results, it is deduced that an increase in the use of solid fuels results in a substantial decrease in the probability of children enrolling in primary and/or secondary education. This lack of education has been seen to result in a high levels of illiteracy, shortage of educated professionals in the labor force, amongst other factors which are contributing to lack of economic growth. As such, the implications of the results obtained from these variables can be termed momentous.

Consequently, more attention needs to be placed on the issue of lack of access to clean cooking fuel. However, for effective solutions will be designed, a better understanding of the issue and its underlying factors is crucial. As a starting point, in this paper, we have briefly discussed some of the barriers to the access of clean cooking fuel but it is imperative to note that there are other cultural, social and geographical barrier which have to be considered in order to address the problem. Based on the barriers considered in this paper, a starting point for addressing the situation could be for governments within the affected regions to establish national databases which provide detailed information on the energy profile of the population. To exemplify, in most countries in Africa, there is a lack of data regarding the energy composition of households. Data illustrating what types of stoves households use; the specific type of fuel households utilise for cooking; cost components; amongst other information, are lacking. In addition, data on potential fuel sources; stoves types; cost analyses and estimates of the ability and willingness to pay, as a function of income; could equip policy makers with the essential information needed to design more efficacious policies.

In terms of addressing the infrastructure barrier, besides developing and improving energy and basic infrastructures in these regions, an effective strategy could be the development of smallscale local energy resources. This strategy could be particularly useful in regions where lack of basic infrastructures such as roads, could physically and/or financially, hinder the development of energy infrastructures.

Finally, to address the issue of financial barrier: a challenge especially daunting for the population in Asia and Africa, where income tends to be low and in some cases, volatile; financial aid in the way of subsidies, grants, etc., will be required to assist poor households get onto the modern fuel ladder. In addition, policies to address energy poverty would need to go hand in hand with broader policies aimed at alleviating income poverty and promoting economic development.

\section{REFERENCES}

[1] B. Lin and X. Ouyang, "Energy demand in china: Comparison of characteristics between the us and china in rapid urbanization stage," Energy Conversion and Management, vol. 79, no. Supplement C, pp. 128 - 139, 2014.

[2] R. Fouquet and P. J. Pearson, "Past and prospective energy transitions: Insights from history," Energy Policy, vol. 50, no. Supplement C, pp. 1 - 7, 2012. Special Section: Past and Prospective Energy Transitions - Insights from History.

[3] C. Rhl, P. Appleby, J. Fennema, A. Naumov, and M. Schaffer, "Economic development and the demand for energy: A historical perspective on the next 20 years," Energy Policy, vol. 50, no. Supplement C, pp. 109 - 116, 2012. Special Section: Past and Prospective Energy Transitions - Insights from History.

[4] World Bank Group, "World Development Indicators," tech. rep., World Bank Group (WB), Washington DC, 2016.

[5] International Energy Agency (IEA), United Nations Development Programme (UNDP), "Energy Poverty: How to make modern energy access universal?," Tech. Rep. September, 2010.

[6] World Bank Group, "Clean and Improved Cooking in SubSaharan Africa," Tech. Rep. 98664, World Bank Group, Washington DC, 2014.

[7] United Nations, "Work of the Statistical Commission pertaining to the 2030 Agenda for Sustainable Development," 2017.

[8] M. Zeshan, "Finding the cointegration and causal linkages between the electricity production and economic growth in pakistan," Economic Modelling, vol. 31, no. Supplement C, pp. $344-350,2013$.

[9] A. Omri and B. Kahouli, "Causal relationships between energy consumption, foreign direct investment and economic growth: Fresh evidence from dynamic simultaneousequations models," Energy Policy, vol. 67, no. Supplement C, pp. $913-922,2014$.

[10] The World Bank, "World development indicators," 2017.

[11] International Energy Agency (IEA), "Africa Energy Outlook: A Focus on Prospects in Sub-Saharan Africa," tech. rep., International Energy Agency (IEA), Paris, 2014.

[12] International Energy Agency, "Energy for Cooking in Developing Countries," World Energy Outlook 2006, pp. 419445, 2015.

[13] S. C. Bhattacharyya, Energy Access and Development. John Wiley and Sons, Ltd., Publication, first edit ed., 2013.

[14] N. G. Bruce, K. Aunan, and E. A. Rehfuess, "Materials on Development Financing." 2017.

[15] S. Malla and G. R. Timilsina, "Household Cooking Fuel Choice and Adoption of Improved Cookstoves in Developing Countries A Review." 2014.

[16] World Bank Group, "Clean and Improved Cooking in SubSaharan Africa," Tech. Rep. 98664, World Bank Group, Washington DC, 2014.

[17] S. L. Nkomo, S. Desai, and K. Peerbhay, "Assessing the conditions of rural road networks in South Africa using visual observations and field-based manual measurements: A case study of four rural communities in Kwa-Zulu Natal," Review of Social Sciences, vol. 1, no. 2, 2016.

[18] S. R. Khandker, Z. Bakht, and G. B. Koolwal, “The poverty 
impact of rural roads: Evidence from bangladesh," Economic Development and Cultural Change, vol. 57, no. 4, pp. 685-722, 2009.

[19] Y. Fukubayashi and M. Kimura, "Improvement of rural access roads in developing countries with initiative for selfreliance of communities," Soils and Foundations, vol. 54, no. 1, pp. 23 - 35, 2014. Special Issue on 2nd International Conference on Transportation Geotechnics ISHokkaido2012.

[20] R. Baldick, R. Grant, and E. Kahn, "PWP-078 Linear Supply Function Equilibrium: Generalizations, Application, and Limitations Linear Supply Function Equilibrium: Generalizations, Application, and Limitations Linear Supply Function Equilibrium: Generalizations, Application, and Limitations," no. February 2001, 2000.

[21] W. Akpalu, I. Dasmani, and P. B. Aglobitse, "Demand for cooking fuels in a developing country: To what extent do taste and preferences matter?," Energy Policy, vol. 39, no. 10 , pp. $6525-6531,2011$. Sustainability of biofuels.

[22] S. C. Bhattacharyya, "Energy access programmes and sustainable development: A critical review and analysis," Energy for Sustainable Development, vol. 16, no. 3, pp. 260 271, 2012.

[23] D. Palit and S. C. Bhattacharyya, "Adoption of cleaner cookstoves: barriers and way forward - Debajit Palit Academia.edu," Tech. Rep. 64, 2014.

[24] S. Energy and F. O. R. All, "Sustainable Energy for All Advisory Board Update on the Se4All High Impact Opportunity : Se4All Hio Universal Adoption of Clean Cooking Solutions," Tech. Rep. May, Global Alliance for Clean Cookestoves, New York, 2015.

[25] M. A. Jeuland and S. K. Pattanayak, "Benefits and costs of improved cookstoves: Assessing the implications of variability in health, forest and climate impacts," PLOS ONE, vol. 7, no. 2, 2012.

[26] Energy Sector Management Assistance Program ESMAP and Sustainable Energy for All, "Beyond Connections Energy Access Redefined," tech. rep., The Energy Sector Management Assistance Program, Washington DC, 2015.

[27] E. A. Hanushek, L. Woessmann, E. A. Jamison, and D. T. Jamison, "Education and economic growth," Education Next, vol. 8, Spring 2008. Name - Organization for Economic Cooperation and Development; Copyright - Copyright Education Next Spring 2008; Last updated - 2017-1120; SubjectsTermNotLitGenreText - United States-US.

[28] S. Klasen and F. Lamanna, "The impact of gender inequality in education and employment on economic growth: New evidence for a panel of countries," Feminist Economics, vol. 15, no. 3, pp. 91-132, 2009.

[29] E. Hanushek and L. Wößmann, "The Role of Education Quality in Economic Growth The Role of School Improvement in Economic Development." 2007.

\section{ACKNOWLEDGMENT}

I would like to express my gratitude to Dr. Robert Rogerson at the Institute of Future Cities (IFC) for his brilliant insights. 